\title{
RESEÑA
}

\section{HISTÓRICAS. MOVIMIENTOS FEMINISTAS Y DE MUJERES EN CHILE, 1850-2020. Ana Gálvez Comandini (coord). Editorial LOM, 2021*}

\author{
Iris Hernández Morales ${ }^{* *}$
}

La circulación de Históricas es un hecho político no solo porque ordena la historia feminista chilena, visibilizando las formas en que este movimiento ha reproducido lo social. También lo es porque moviliza reflexiones acerca del saber que piensa de un solo modo, cuestión que desarrollo introductoriamente a partir de estos comentarios respecto del libro para afirmar que sus contenidos nos acercan a un saber que piensa de otras formas.

Históricas exhibe las luchas de mujeres feministas y no, que sostienen los feminismos de hoy y que en muchos casos han sido negadas por la historia oficial escrita, por cierto, por hombres hegemónicos. Estas luchas con base en privilegios de clase, raza, sexualidad habitan en la memoria feminista de modo más y menos visible. Así expongo dos de sus aportes fundamentales: la ampliación de la memoria y la exhibición de una relación desequilibrada entre feminismos que cuestionan su cohesión, la verdad de algunos de sus idearios y la opacidad en la que habitan mujeres de pueblos originarios y afros en sus planteamientos.

Con su acto de tejer ciento setenta años de historia feminista, Históricas tensiona, por ejemplo, que la clase nos divide y el género nos une. Basta pensar en la denuncia de mujeres obreras a finales del siglo XIX por la afinidad del esquema de emancipación de género con el modelo burgués de participación electoral que hoy persiste en voces autónomas o en la desconexión entre los procesos que llevaron a Eloísa Díaz a ser la primera médica chilena y los que llevaron a la costurera Micaela Cáceres, sin mayor educación formal, a ser una de las fundadoras de la Sociedad de Socorros Mutuos. Estas luchas no redujeron las diferencias capitalistas entre mujeres. Tampoco el racismo, porque es probable que las luchas de Silvia Pichun o Verónica Catrileo -recogidas por el libro-sean desconocidas

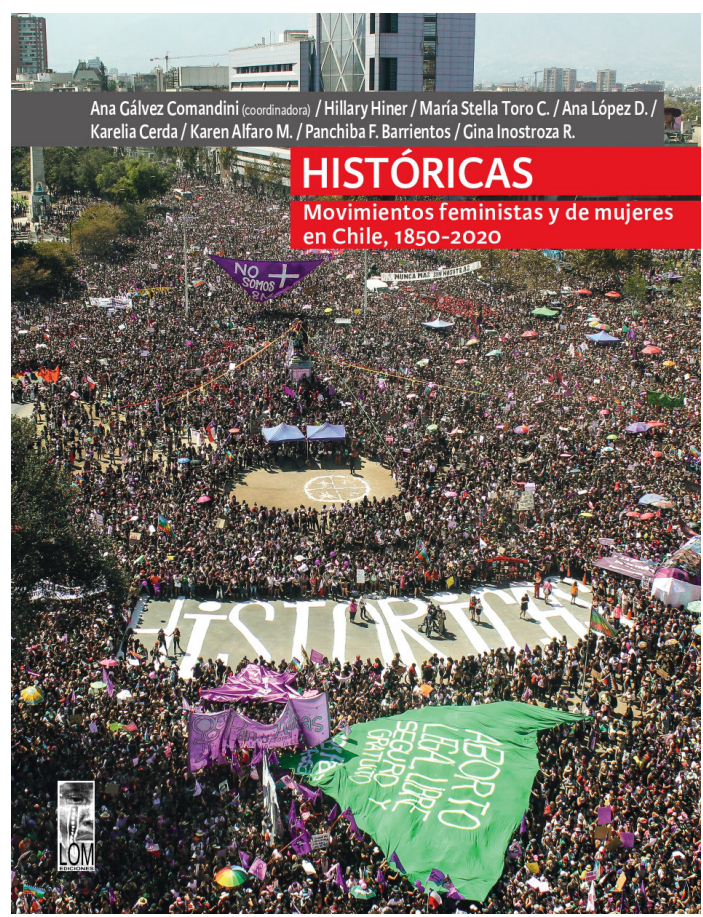

para una mayoría feminista. Si sumo que las mujeres de pueblos originarios no ingresaron a la Universidad por una lucha feminista específica se vislumbra un saber que al pensar de un solo modo ha producido activamente que una mujer que siembra la tierra no sea referente feminista (Espinosa, 2020).

El carácter genealógico del trabajo permite lo anterior al exponer tensiones recurrentes ligadas al universalismo de su sujeta política, a la militancia partidista, a la disputa por la noción de autonomía, entre otros. Esto que remueve narrativas totalizadoras nos acerca a percibir que no existe una definición respecto de feminismo válida para todas las feministas y épocas y que los logros de este movimiento siempre le han servido más a algunas mujeres. Y es que, sin

\footnotetext{
* El texto adapta la versión original de la presentación del libro realizada el 25/03/2021. Esta se encuentra en https://www. youtube.com/watch?v=wRAnVFS9dlY

** Activista lesbofeminista antirracista descolonial. Doctora en Estudios Latinoamericanos.
} 
desligarse de la relación entre lo local, lo regional, lo transnacional, Históricas ilumina claroscuros que nos interpelan acerca de cómo hemos llegado a ser las feministas que somos y creer en lo que creemos.

Las respuestas son complejas. Yo destaco la disputa epistémica entre un saber fragmentario y uno relacional que queda por debajo de este. Este desequilibrio fundamenta que Históricas pueda recoger diversos logros feministas vinculados al derecho moderno y pocos vinculados a la transformación del modelo económico, lo que ayuda a explicar por qué en los debates feministas las luchas por la defensa de los territorios hayan demorado tanto en aparecer. Estas luchas -sostenidas por un Saber en donde la naturaleza, las cosas y seres solo existen en relación con Otrxs- entienden con más agilidad que el ingreso de Eloísa Díaz a la Universidad requirió que mujeres como Micaela no lo hicieran. Asimismo, comprende que el protagonismo histórico de la disputa entre estas luchas acaecidas en territorios visibles para la Modernidad produce a lxs Otrxs del feminismo que la misma Modernidad inscribe en territorios de lo invisible.

¿Cómo habría sido conjugar la demanda por ingresar a la Universidad con las que sostuvieron la Sociedad de Socorros Mutuos? ¿Cómo sería nuestro hoy si ayer las feministas hubiesen pensado con las experiencias producidas al fragor racista de la precariedad capitalista? Históricas sin afán antagonista promueve estas preguntas, azuzando la alerta: si las demandas de unas se transforman en la liberación de todas es por una práctica adaptada al saber que piensa de un solo modo. Esto levanta desafíos asociados a la escucha y encuentro con experiencias desoídas para correr el cerco de las prescripciones en torno a quién y cómo es la mujer feminista liberada.

Lo anterior se sustenta en un tejido que no separa la teoría de la acción, cuestión que vinculo a que las autoras del libro además de académicas son activistas. De allí que no nieguen la contingencia y defiendan que la investigación es lucha que afirma la co-construcción de saberes. Esto favorece lecturas que no separan los logros feministas de lo que estos mismos logros ocultan, facilitando que prestemos atención a lo que queda por debajo de lo que ha sido tratado como historia para confrontar el carácter monocultural de una comunicación feminista que se ha realizado en modalidad dominante, es decir, fragmentaria, antagónica, jerárquica, binaria.

De esta manera -y sometida a mis intereses políticos condición sine qua non para las lecturas que el libro movilizará- Históricas interpela la completud feminista que habita, por ejemplo, en la afirmación "La revolución será feminista o no será" en donde late un saber feminista que renuncia a pensar cuando cree que sus términos representan a todas las personas y son los únicos que se deben aprender. Esta completud -refuerzo- no habita en Históricas, ya que no defiende ideas de un diseño universal feminista. Por el contrario, en sus páginas se visualizan centros, periferias y desafíos feministas, activando una lectura que hoy más que ayer no desagrega el patriarcado del colonialismo y el capitalismo, base de las sobreposiciones comentadas y que emanan del saber que piensa de un solo modo.

De otra forma dicho: Históricas ilumina discusiones que no son nuevas, rebatiendo la completud occidental, ayudando a que los saberes dominantes sean reutilizados contrahegemónicamente, porque recoge los desechos producidos por la historia oficial. Entender que nuestras prácticas no tienen sentido por sí mismas, pues estas se forjan en la red de relaciones que nos co-constituyen amplía las alternativas de transformación, pues demanda asumir que somos al mismo tiempo solución y problema, lo que es semilla que transforma la resistencia feminista en re-existencia.

Sintetizando: Históricas abre la puerta a percibir nuestra incompletud posibilitando el desmontaje de las relaciones coactivas entre feminismos. Esto afirma una transformación del Ser feminista para que aun cuando estemos del lado dominante nos esforcemos por saber y pensar con, desde y entre los lados no dominantes. Escucharnos es fundamental y en este camino el trabajo de estas ocho activistas de la Red de Historiadoras Feministas -que se transformará, sin duda, en una fuente de consultas y referencias ineludible-impulsa el reconocimiento y valoración de diversas historias, construyéndose a partir de estas, de sus límites, de los retornos y fugas, un saber feminista comprometido con pensar de otro modo.

\section{Referencias Citadas}

Espinosa, Y.

22 de agosto 2020 "El ideal de mujer del feminismo implica la explotación de la mayoría de mujeres y varones extraeuropeos" https://ctxt.es/es/20200801/Politica/33177/ yuderkys-espinosa-feminismo-colonialismo-amandaandrades.htm 